\title{
PARQUES DO BRASIL: A CONSERVAÇÃO DA BIODIVERSIDADE COMO PROMOÇÃO DA SAÚDE E DA QUALIDADE DE VIDA
}

Luciana Alvarenga ${ }^{1}$

Carlos Sanches ${ }^{2}$

Márcia Muchagata ${ }^{3}$

Resumo: Ao produzir uma série de TV sobre a biodiversidade nos parques nacionais brasileiros, a equipe coordenadora do projeto faz uma reflexão a partir das experiências vivenciadas em campo e da história ambiental do Brasil, apresentando subsídios para o desenvolvimento de uma economia mais sustentável, que promova também a saúde e a qualidade de vida, através da implementação de unidades de conservação e do uso indireto de seus recursos naturais.

Palavras-chave: Unidades de Conservação; Educação Ambiental; Produção Audiovisual; Serviços Ecossistêmicos.

Abstract: Parks of Brazil is a TV documentary series presenting issues related to the biodiversity of Brazilian National Parks. The series coordination team reflects on Brazil's environmental history, based on their fieldwork experience, providing subsidies for the development of a more sustainable economy able to promote health and quality of life, through the implementation of protected areas and the indirect use of their natural resources.

Keywords: Protected Areas; Environmental Education; Audiovisual Production; Ecosystem Services.

${ }^{1}$ Fundação Oswaldo Cruz. E-mail: luciana.alvarengafiocruz.br.

Link para o Lattes:http://lattes.cnpq.br/6760214622764807

2 Empresa Brasil de Comunicação. E-mail: carlos.sanches@ebc.com.br.

Link para o Lattes:http://lattes.cnpq.br/6880411126484719

${ }^{3}$ Fundação Oswaldo Cruz. E-mail: marcia.muchagata@fiocruz.br.

Link para o Lattes:http://lattes.cnpq.br/0801027670383647

Revbea, São Paulo, V. 15, № 5: 230-249, 2020. 


\section{Introdução}

Enquanto a pandemia de Covid-19, com todas as suas terríveis consequências sociais e econômicas, impõe restrições ao movimento de pessoas, os parques nacionais e outras unidades de conservação também estão sendo impactados de diversas formas (JACQUES; BHALLA, 2020). A queda do turismo afeta desde guias turísticos até comunidades locais, assim como dificulta a ação daqueles que trabalham pela conservação. Embora o fim da visitação deixe os animais mais livres para circular, como tem sido narrado em vários lugares do mundo (BBC NEWS, 2020; NEWS18, 2020), as unidades de conservação se tornam mais vulneráveis à ação de desmatadores, caçadores e grileiros. Só no Brasil, em abril de 2020, o desmatamento aumentou $171 \%$ em comparação com o ano anterior (FONSECA et al., 2020), mas tendências semelhantes estão em curso em outros países, como Colômbia (BBC, 2020), Indonésia e Malásia (TAYLOR, 2020).

Não sabemos se o turismo e as ações de conservação irão voltar a níveis e padrões próximos ou semelhantes aos anteriores, mas é cada vez mais claro que o papel de conservação dos habitats naturais é imprescindível para o futuro da humanidade. Isso não apenas por questões relacionadas aos serviços ecossistêmicos prestados por essas áreas, mas também por questões de saúde. Três quartos dos patógenos emergentes que infectam os seres humanos surgiram de animais, e a maioria deles vive nos habitats naturais que estamos destruindo. Também concentramos esses animais em áreas menores, facilitando a circulação de microorganismos infecciosos e aumentando as chances de novas cepas (SCIENTIFIC AMERICAN EDITORS, 2020). OLIVERO et al. (2017) demonstraram, para o caso do Ebola, que a maior probabilidade de surto está ligada ao desmatamento, e que essa possibilidade pode ser reduzida através da conservação da floresta. Várias pesquisas têm alertado sobre o papel das alterações ambientais nas condições de saúde humana. A atual pandemia sugere que esforços de conservação são fundamentais para a prevenção de riscos à saúde e para a mitigação das graves consequências que eventos como esse produzem, mesmo que seu único benefício direto seja reduzir o acontecimento desses eventos (DOBSON et al., 2020).

Nesse contexto, todas as ações que fortaleçam a educação ambiental são de extrema importância. Em tempos de pandemia, o papel da produção audiovisual e o acesso à informação por meio digital como forma de levar informação sobre questões ambientais fica muito mais evidente. Este artigo trata da experiência de um projeto que elabora e disponibiliza documentários de curta e média metragens sobre os ecossistemas e a biodiversidade das unidades de conservação brasileiras, revelando a relação dessas áreas protegidas com a qualidade de vida e a saúde.

Denominada Parques do Brasil (SANCHES; ALVARENGA, 2019), esta série de documentários começou a ser desenvolvida em 2012. O momento inicial deste processo foi marcado por atividades de prospecção e trabalhos de 
campo nos Parques Nacionais do Itatiaia (RJ/MG), da Tijuca (RJ) e da Serra dos Órgãos (RJ), e, nos Parques Estaduais do Ibitipoca (MG), da Ilha Grande (RJ) e da Pedra Branca (RJ). Entre 2013 e 2015, foram realizadas pesquisas com 18 comunidades no entorno do Parque Nacional da Serra da Bocaina $(\mathrm{RJ} / \mathrm{SP})$, da Reserva Ecológica da Juatinga (RJ) e do Parque Estadual de Itaúnas (ES). Em 2014, aconteceram as primeiras gravações no Parque Nacional da Chapada Diamantina (BA). $O$ Projeto se consolidou institucionalmente através de um Convênio e de um Acordo de Cooperação Técnica inter-relacionados, envolvendo três instituições públicas: a Casa de Oswaldo Cruz-COC/FIOCRUZ, a Empresa Brasil Comunicação-EBC e o Instituto Chico Mendes de Conservação da Biodiversidade-ICMBio. Entre 2015 e 2019, a equipe do projeto esteve 292 dias em campo, realizando viagens através de todas as regiões do país. Essas atividades reuniram equipes de 22 unidades de conservação federais, envolvendo, num processo colaborativo, técnicos de produção audiovisual, biólogos, analistas ambientais, historiadores, brigadistas, guias de turismo e de observação de aves, professores e pesquisadores de universidades públicas, entre outros.

$\mathrm{Na}$ primeira parte do artigo são apresentados os impactos das atividades humanas em diferentes biomas brasileiros, relacionando-os com 0 Antropoceno e a história ambiental do país. Na segunda e na terceira partes, revelaremos a importância das unidades de conservação na mitigação desses impactos e na promoção da saúde e da qualidade de vida, bem como no desenvolvimento da ciência. Fechando o artigo, apresentaremos as unidades de conservação como um instrumento de desenvolvimento sustentável e o papel da produção audiovisual como suporte à educação e à conservação ambiental no pós-pandemia.

\section{Os impactos do Antropoceno na realidade brasileira}

A maioria das expedições do Projeto foi realizada através de viagens terrestres, proporcionando não só experiências e registros sobre os ecossistemas encontrados nas unidades de conservação brasileiras, mas, ao percorrer os espaços entre essas unidades, possibilitou o estabelecimento de um amplo painel sobre os impactos relativos aos usos do solo e de vários outros recursos naturais, promovidos por diferentes atividades econômicas. Boa parte desses caminhos foi percorrida mais de uma vez, algumas vezes no período de poucos meses, outras após alguns anos. Essa experiência gerou impressões sobre o acelerado processo de transformação que ocorre em algumas regiões do país, além de revelar fenômenos naturais e antrópicos específicos, cíclicos ou extraordinários.

Tudo o que vimos e registramos durante as expedições faz parte e é resultado de um processo histórico, promovido através de uma sequência de ciclos econômicos, que se inicia com o advento colonizatório no século XVI, mas que se problematiza com a progressiva globalização da economia 
promovida a partir do final do século XVIII, com a denominada Revolução Industrial. Segundo Hobsbawm (2015, p. 59)

"na década de 1780, e pela primeira vez na história da Humanidade, foram retirados os grilhões do poder produtivo das sociedades humanas, que daí em diante se tornaram capazes de multiplicação rápida, constante, e até o presente ilimitada, de homens, mercadorias e serviços".

Produzindo sua própria demanda e promovendo o consumo, este processo teve como base a utilização dos combustíveis fósseis e de vários outros recursos naturais. Além de desencadear profundas transformações políticas, econômicas, tecnológicas e sociais, ao desenvolver uma série de atividades produtivas correlacionadas, provocou, de maneira progressiva e cada vez mais ampla, a conversão dos ecossistemas naturais em áreas de cultivo, pastagens, estradas, cidades, entre outros.

Tal foi o impacto gerado por este modelo de desenvolvimento econômico, que a impressão humana no ambiente global passou a afetar o funcionamento da Terra enquanto sistema. A este advento foi cunhado o termo "Antropoceno" (STEFFEN et al., 2012).

Atravessando diferentes regiões do país, é possível identificar os reflexos desse processo histórico e, por sua vez, do Antropoceno nos diferentes biomas. Por conta de sua extensão territorial, o Brasil apresenta uma enorme diversidade de ecossistemas distintos, agrupados em seis domínios morfoclimáticos e fitogeográficos terrestres: a Mata Atlântica, o Cerrado, a Caatinga, a Amazônia, o Pantanal e o Pampa. Durante a realização do projeto até o presente, foram registrados ecossistemas naturais e antropogênicos em cinco desses biomas. Cada um desses domínios possui uma história particular.

\section{Mata Atlântica}

A Mata Atlântica é caracterizada por diferentes tipos de florestas que cobrem a região litorânea do Nordeste ao Sul do país. Nesta região específica, entra pelo interior do continente até encontrar a Bacia do Rio Paraná, na fronteira com a Argentina e o Paraguai. Este domínio foi o primeiro a ser afetado pela colonização europeia, principalmente devido à sua localização ao longo do litoral. No início do século XVI, cobria cerca de $1.315 .460 \mathrm{~km}^{2}$ (IBGE, 2004), apresentando, já nessa época, alguns impactos localizados, decorrentes das populações indígenas que ali viviam de cultivos de subsistência e de extrativismos diversos (DEAN, 1996), mas nada que pudesse se comparar ao que viria acontecer depois de cinco séculos de exploração. Palco de sucessivos ciclos econômicos como a cana-de-açúcar, o fumo, a extração de madeira, a pecuária, o café e a mineração, no meio dessa floresta foram surgindo as maiores cidades brasileiras, e o país foi, aos poucos, se industrializando (PRADO JÚNIOR, 2008; DEAN, 1996). Os rios que a drenam 
foram barrados por centenas de hidrelétricas e represas, abastecendo ainda uma população de mais de 145 milhões de pessoas, numa região que produz $70 \%$ do PIB nacional (SOSMA, 2018). Com isso, hoje restam apenas $12,4 \%$ da floresta que havia antes (INPE, 2018).

Esse radical processo de conversão dos ambientes naturais produziu consequências que são facilmente constatáveis e, em sua maioria, visíveis. Da mata que havia antes, sobraram apenas fragmentos de florestas de variados tamanhos - principalmente em áreas de pouco interesse aos processos produtivos de médio e grande porte -, como regiões montanhosas. Boa parte dessas ilhas de habitat não são contínuas e estão todas cercadas por extensas áreas antropizadas. Os rios que vemos pelo caminho, fora das unidades de conservação, como o Paraíba do Sul, no vale homônimo, que "disponibiliza água para mais de 17 milhões de pessoas" (INEA, 2014), são superexplorados, excessivamente represados e estão poluídos e assoreados.

Percorrendo os estados de Rio de Janeiro, São Paulo, Minas Gerais, Espírito Santo, Bahia e Paraná, essa realidade se repete e encontramos unidades de conservação cada vez mais isoladas, como a Reserva Biológica de Sooretama (ES) e todas as unidades da Costa do Descobrimento. No Brasil, o Parque Nacional do Iguaçu (PR) é o que restou de uma imensa floresta semidecídua e mista, que foi devastada em menos de um século. As matas protegidas dos Parques Nacionais do Itatiaia e da Serra dos Órgãos se mantiveram a salvo por estarem em áreas economicamente inadequadas e, hoje, encontram-se cercadas por ambientes degradados e por estradas. A Mata Atlântica é emblemática no sentido de revelar as radicais transformações que as atividades humanas podem acarretar aos sistemas naturais. E sua história é o ponto de partida para a história da exploração dos outros biomas brasileiros.

\section{Caatinga}

Mesmo onde aparentemente não havia condições para 0 desenvolvimento econômico, ele ocorreu. O interior do Nordeste apresenta um conjunto de ecossistemas adaptados à escassez de água. Considerado único domínio integralmente brasileiro, a Caatinga é tida como a região semiárida de maior concentração humana do mundo. Por conta de suas características climáticas, o seu processo histórico de ocupação e de uso do solo foi lento. Partindo da Bahia e de Pernambuco no século XVII, a pecuária se estabeleceu como a base econômica dessa região, tendo como importantes parâmetros a disponibilidade local de água e o uso do fogo na abertura de áreas para pastagens (SILVA; BARBOSA, 2017; PRADO JÚNIOR, 2008). É uma ocupação irregularmente distribuída, composta por fazendas de gado espacialmente afastadas umas das outras, conectadas por vias onde acabaram surgindo pequenas vilas de apoio a essa atividade, geralmente no entorno de cacimbas de água ou ao longo de rios perenes, como o São Francisco. O apogeu dessa economia se deu no século XVIII, quando o gado ali produzido abastecia boa parte do litoral. Mas esse momento de aparente pujança logo foi 
suplantado pela produção vinda do sul do país e o interior nordestino entrou em decadência profunda (PRADO JÚNIOR, 2008). No século XX, inovações tecnológicas e de infraestrutura voltam a promover 0 desenvolvimento econômico da região, impactando ainda mais os ecossistemas naturais (SILVA; BARBOSA, 2017). Ocupando uma área de $844.453 \mathrm{~km}^{2}$ (IBGE, 2004), o bioma apresenta hoje $63,3 \%$ da sua área convertida em sistemas antropogênicos (SILVA; BARBOSA, 2017), como plantações, pastagens, áreas degradadas algumas em processo acelerado de desertificação -, estradas, entre outras.

No sertão baiano registramos áreas de caatinga degradada e vastos empreendimentos agropecuários no entorno dos parques nacionais da Chapada Diamantina e de Boa Nova. Nas proximidades do primeiro, os usos da irrigação artificial e de agroquímicos estão convertendo áreas nativas em plantações de grãos. No segundo, observamos de perto a degradação de ecossistemas que, por conta das condições climáticas regionais e locais semiáridas, apresentam uma capacidade de resiliência menor e mais lenta, em comparação com ecossistemas de regiões com mais disponibilidade de água.

\section{Cerrado}

No Cerrado, as limitações ambientais e estruturais também só foram solucionadas no século XX. No final do XVII, as bandeiras paulistas encontraram as primeiras jazidas de ouro, onde hoje é o estado de Minas Gerais. Daí então, atravessando boa parte do século seguinte, a busca e a exploração desse minério e, logo depois, do diamante, promoveram o estabelecimento de pequenas concentrações humanas onde hoje são os estados de Goiás e do Mato Grosso. A pecuária acompanhou esse processo exploratório e, ao fim dele, transformou-se na principal atividade produtiva de uma região imensa e relativamente deserta no interior do país (PRADO JÚNIOR, 2008).

Após um período de estagnação durante o Império, surge em 1930, com o Estado Novo, "uma dinâmica socioeconômica e política que incorpora o ideário nacional de desenvolvimento por meio da ocupação e interligação dos territórios, até então caracterizados como sertão", e o Brasil Central passa a ser alvo de incentivos para a sua "recolonização", que tem seu marco na construção e inauguração de Brasília - nova capital do país -, em 1960, provocando, já na sua construção, um grande afluxo de imigrantes (PRADO JÚNIOR, 2008).

A partir da década de 1950, são realizados estudos agronômicos com vistas à ampliação do cultivo no Cerrado, que desencadeiam a chamada "revolução verde" da década de 1970, com o estabelecimento de programas como o Polocentro (Programa de Desenvolvimento dos Cerrados), de 1975, e o surgimento de uma série de tecnologias que possibilitaram a incorporação de vastas áreas naturais, antes consideradas inadequadas para a agricultura, ao sistema produtivo (DELLA GIUSTINA, 2013). Por conta desse processo acelerado de conversão, em 2017 , somente $55 \%$ da sua área original, de 
aproximadamente 2 milhões de $\mathrm{km}^{2}$, apresentava-se coberta por vegetação nativa (ALENCAR et al., 2020). E o cultivo de soja, milho e algodão, entre outras culturas, continua a se expandir no bioma, principalmente nas áreas de menor declividade, mais adequadas à utilização do moderno maquinário do agronegócio atual.

Durante as expedições através de interior do Brasil Central, passando por São Paulo, Minas Gerais, Goiás, Mato Grosso e Mato Grosso do Sul, registramos extensas áreas convertidas em cultivos ou destinadas a pastagens, plantadas ou não. Nas estradas que percorremos, os automóveis eram os veículos em menor número, já que havia enormes comboios de carretas carregadas de grãos se deslocando em direção ao litoral e, no sentido contrário, subindo, objetivando um novo carregamento. Da divisa dos estados do Mato Grosso e Mato Grosso do Sul até Cuiabá, a paisagem parece homogênea, intercalando um rio ou outro no caminho, onde muitas vezes a mata ciliar se apresentava degradada pelo fogo, provavelmente criminoso. Fora da $B R$, estradas menores cortavam campos plantados que pareciam não ter fim, isso tudo para chegarmos em alguma unidade de conservação. As distâncias entre as unidades de conservação integrais do Cerrado são enormes e muitas delas só não se encontram completamente isoladas devido aos rios que nascem dentro delas ou as percorrem, criando corredores naturais, que ligam essas unidades com outras áreas naturais fora delas.

As pequenas cidades no interior dessa região se transformaram em bases de apoio ao agronegócio, mais parecendo enormes pátios de fábricas, com trabalhadores vestidos com macacões e capacetes. Nas imensas fazendas observa-se somente o vaivém das carretas e das máquinas de colheita ou de aplicação de agroquímicos e sementes, trabalho esse que, em alguns períodos do ano, é de 24 horas por dia. E vemos essas máquinas iluminadas no meio da noite atravessando o que era antes coberto pelo Cerrado. Numa manhã, quando passávamos de janelas abertas, fomos quase sufocados pelo cheiro de agrotóxicos que são transportados em caminhõestanque. Os trabalhadores desses caminhões utilizam um EPI que lembra a vestimenta de um astronauta. Em alguns momentos, enquanto um trator pulverizava o agrotóxico pelo terreno, um monomotor sobrevoava a mesma área, lançando sobre ela uma nuvem de compostos químicos.

Essas imagens se repetem por todo o percurso entre uma unidade de conservação e outra, mas são emblemáticas do entorno do Parque Nacional das Emas. Localizado na divisa dos estados de Goiás, Mato Grosso e Mato Grosso do Sul, essa unidade, criada no início desse processo radical de conversão do Cerrado, em 1960, protege uma ilha de habitat com 1.318,64 km² (IBAMA, 2004). De início, o que mais chama a atenção é que não existe no entorno desta unidade uma zona de amortecimento, como deveria ser, de acordo com a legislação. Os limites da unidade demarcam exatamente onde o Cerrado termina e começa a plantação. Além da cerca, somente uma estreita estrada de monitoramento (no interior do parque) "separa" as duas áreas e seus usos.

Revbea, São Paulo, V. 15, № 5: 230-249, 2020. 
Apesar das particularidades locais, o padrão de isolamento progressivo se repete em outras unidades de conservação do bioma. No Parque Nacional da Chapada dos Guimarães, próximo de Cuiabá, capital do estado do Mato Grosso, a taxa de conversão das áreas do entorno aumenta a cada ano, apesar de as características geomorfológicas da unidade possibilitarem ainda conexões com outras áreas verdes, principalmente através dos rios que a atravessam.

No Parque Nacional da Serra da Canastra, localizado no sudoeste do estado de Minas Gerais, perto da divisa com o estado de São Paulo, os conflitos fundiários oriundos da época de sua criação, em 1972, acabaram levando os impactos para dentro da própria unidade, que apresenta duas áreas distintas interligadas, uma legalmente estabelecida - o Chapadão da Canastra -, outra em lento processo de regularização - o Chapadão da Babilônia. Neste último, os vales continuam sendo utilizados para inúmeras atividades agrárias, incluindo extensas plantações de milho e a criação de gado bovino. Este trecho sofre ainda com a mineração ilegal de quartzito, entre outras atividades altamente impactantes para os ecossistemas em recuperação da unidade e para a biodiversidade. Mesmo o trecho legalizado apresenta conflitos: a maior parte dos incêndios que atingem o parque tem origem antrópica (IBAMA, 2005). No entorno da unidade, as atividades produtivas de maior escala se expandem, como a monocultura do eucalipto.

\section{Pantanal}

A expansão da agricultura no Cerrado, com a utilização maciça de agroquímicos e da irrigação artificial, bem como o estabelecimento de barragens e de pequenas hidrelétricas, tem ameaçado um bioma que, apesar de mais de dois séculos de pecuária extensiva, apresenta ainda cerca de $80 \%$ da sua área coberta por ecossistemas naturais (MAPBIOMAS, 2018).

O Pantanal é um bioma compartilhado com a Bolívia e o Paraguai, e ocupa no Brasil uma área de $150.355 \mathrm{~km}^{2}$ (IBGE, 2004). Composto por formações florestais e campestres, com grande predomínio de áreas alagadas e corpos hídricos, o bioma impõe limitações às atividades de cultivo, mas sofre as consequências de ser um sistema conectado ao Cerrado. A planície pantaneira surgiu com o soerguimento dos Andes e do Planalto Central brasileiro (FRANCO et al., 2013), transformando-se numa área de baixada com pouquíssima declividade, por onde se espalha a bacia do Rio Paraguai. Este rio, bem como seus principais afluentes, nascem no Cerrado. Barragens como a de Manso já interferem na dinâmica natural desse sistema (UMETSU, 2004). A contaminação química decorrente dessa expansão agrícola e seus impactos na biota já são tema de estudos (CECCATO et al., 2015).

Durante as duas expedições que realizamos na região, explorando a Estação Ecológica de Taiamã e o Parque Nacional do Pantanal Matogrossense, tivemos a oportunidade de conhecer um projeto que, se implantado, pode vir a trazer impactos severos e ainda pouco estudados nos 
frágeis ecossistemas do bioma. O projeto de hidrovia Paraguai-Paraná afeta diretamente as duas unidades de conservação e prevê uma série de obras de engenharia e a passagem de comboios de chatas, provocando distúrbios diversos na área mais conservada do Pantanal, podendo influenciar até a dinâmica do pulso de inundação, fenômeno natural essencial para a vida e a economia pantaneira (ICMBio, 2016).

\section{Amazônia}

A exploração da agricultura, da pecuária e da mineração no Cerrado está avançando através do bioma Amazônico, criando uma enorme faixa de desmatamentos e queimadas, atravessando os estados do Mato Grosso, Rondônia, Acre, Amazonas, Pará e Maranhão. É um processo amplo e acelerado, que destruiu mais de $10.000 \mathrm{~km}^{2}$ de florestas só em 2019 (INPE, 2020). O impacto das queimadas foi tão grande nesse período que durante os deslocamentos até o Parque Nacional do Iguaçu, em setembro do mesmo ano, testemunhamos a passagem de uma tempestade de fuligem. Durante as gravações dessa expedição, o céu se manteve invariavelmente enevoado.

Em outubro, viajamos para o Parque Nacional do Jaú, no Amazonas, uma região que ainda está distante desse círculo de queimadas. Mas lá registramos uma área de cerca de 1.000 hectares que havia sido queimada quatro anos atrás e notamos que o local não apresentava ainda recuperação significativa, expondo a fragilidade dos ecossistemas amazônicos. Compartilhado com vários países da América do Sul, a Amazônia ocupa no Brasil uma área de $4.196 .943 \mathrm{~km}^{2}$ (IBGE,2004), sendo que 17\% (MAPBIOMAS, 2018) do bioma já foram convertidos em áreas antropizadas, principalmente em pastagens.

A alteração e a conversão de mais da metade dos ecossistemas naturais terrestres do mundo, a superexploração de diversos recursos naturais, bem como a disponibilização de compostos químicos antes inativos na biosfera, através da combustão de subprodutos do petróleo, das queimadas de imensas áreas florestais, da introdução de nitrogênio e de pesticidas nos solos, além de diversos outros processos poluidores, entre outros fatores, está colocando em xeque o equilíbrio dos sistemas naturais que permitem a vida no planeta, provocando o sexto advento de extinção em massa de espécies da história da Terra - o único provocado por uma espécie específica (STEFFEN et al.,2012).

Reflexo mais atual desse processo de desequilíbrio sistêmico, a pandemia do Covid-19 provoca, pela primeira vez desde o início da Revolução Industrial, uma freada radical nesse sistema produtivo global, impedindo, ainda que temporariamente, a circulação de pessoas e de produtos, como nunca havia acontecido antes. 


\section{As Unidades de Conservação}

$\mathrm{Na}$ esteira do processo que desencadeou o Antropoceno, houve também o desenvolvimento da ciência, dos meios de comunicação e de transporte, da indústria da arte e de uma série de reações que surgiram com o objetivo de frear, mitigar, controlar, eliminar ou consertar problemas e consequências adversas desse sistema produtivo mundial. Entre essas ações, temos o surgimento de novas configurações político-econômicas e sociais, os direitos humanos e também o estabelecimento das unidades de conservação.

O conceito de áreas protegidas muda conforme os tempos históricos. Sua primeira concepção abrigava a necessidade de preservar áreas de importância religiosa ou histórica. Mais tarde, modifica-se com o objetivo de proteger recursos naturais valiosos, como a madeira ou a caça. Até chegar à sua concepção atual, de promover a conservação da diversidade biológica e de serviços ambientais essenciais (PUREZA et al., 2015). Os parques nacionais surgem no final do século XIX, inicialmente com o intuito de preservar regiões de grande beleza paisagística. Mas isso logo se modifica e os parques passam a combinar três objetivos básicos: a preservação da fauna e da flora, a pesquisa científica e o turismo (FRANCO, 2009).

No Brasil, o estabelecimento de áreas protegidas se deu lentamente e se consolidou com a promulgação da Lei no 9.985, de 2000, que cria o Sistema Nacional de Unidades de Conservação - SNUC. Este define dois grupos de unidades: um, de proteção integral, admite somente o uso indireto de seus recursos naturais; outro, de uso sustentável, permite o uso manejado de determinados recursos. Este sistema cria um amplo leque de tipos de unidades com graus de proteção variados e diferentes objetivos. Essa diversidade possibilita, ao mesmo tempo, a conservação da biodiversidade e o desenvolvimento econômico.

Apesar disso, este sistema provoca conflitos. Na verdade, a criação de unidades de conservação em todo o mundo é um processo lento, marcado pela disputa com diferentes setores da economia. No Brasil, onde a base da economia sempre esteve centrada no uso da terra e na exploração de commodities, a realidade não é diferente e assistimos ao surgimento de uma série de ações que visam o enfraquecimento e o desmantelamento desse sistema. Nos trabalhos de campo realizados, percebe-se que todas as unidades de conservação brasileiras sofrem algum tipo de ameaça. Entre elas, as de proteção integral são as mais ameaçadas (SANCHES; ALVARENGA, 2019).

No país, ronda um discurso falacioso de que existe um excesso de unidades de conservação ou que as mesmas cobrem a maior parte do território brasileiro. Para isso, muitas vezes, os autores dessas falas juntam na mesma conta diferentes tipos de unidades e áreas onde o objetivo central não é a conservação da biodiversidade. Mas, se formos analisar a situação através da perspectiva das áreas que realmente não permitem o uso direto dos seus recursos, ou seja, as de proteção integral, verificamos que esse discurso está 
muito longe da realidade. Somente $6,4 \%$ do território nacional está protegido através de unidades onde não é permitida a exploração dos recursos naturais. Mas esse número genérico também esconde o fato de que a maioria desse território está na Amazônia. E mesmo nesse bioma, somente 10,2\% estão protegidos dessa forma. Na Caatinga, essa porcentagem cai para 2,4\%; no Cerrado, 2,9\%; na Mata Atlântica, 2,6\%; no Pantanal, 2,9\%; e no Pampa, 0,6\% (MMA, 2020).

Para evitar a conversão de ecossistemas naturais em áreas antropogênicas - um dos principais problemas gerados no Antropoceno -, não existe melhor recurso do que o estabelecimento de unidades de conservação, principalmente as de proteção integral. Através dessas unidades, podemos proteger sistemas naturais inteiros, como bacias hidrográficas, serras, manguezais, recifes de corais, entre outros.

Hoje, mesmo ocupando áreas muito menores do que propalado, essas áreas protegidas se constituem como uma base de manutenção da saúde ambiental, criando impactos benéficos tanto localmente, quanto regionalmente. Isso se dá por conta dos inúmeros atributos ecológicos que essas áreas ainda possuem, e pelos serviços ecossistêmicos que prestam às regiões onde elas se inserem e, por sua vez, à sociedade como um todo, envolvendo inclusive serviços ecossistêmicos fundamentais para a perpetuação da vida humana no planeta.

\section{Parques saudáveis, pessoas saudáveis}

A crise ecológica não é uma crise isolada e está diretamente relacionada a outras crises, sobretudo a da saúde humana, como demonstra bem a atual pandemia do Covid-19. Os riscos à saúde relacionados ao Antropoceno são altos, desigualmente distribuídos, e tem a capacidade de atingir o planeta inteiro. No entanto, a literatura sobre saúde pública latinoamericana só incorporou a palavra ecossistema a partir do ano 2000. E, na maioria dos artigos, o ecossistema é tratado apenas como o local de existência de determinado vetor ou patógeno (FREITAS et al., 2007).

Apesar dos esforços promovidos pela Organização Mundial da SaúdeOMS, numa abordagem denominada One Health, "para projetar e implementar programas, políticas, legislação e pesquisa nas quais vários setores se comunicam e trabalham juntos para alcançar melhores resultados de saúde pública" (WHO, 2017), ainda não há reconhecimento suficiente de que a nossa saúde está intimamente ligada à sustentabilidade e à saúde dos ecossistemas. O desmatamento, a fragmentação e a conversão dos ecossistemas naturais, o crescimento urbano desordenado e, de uma forma ainda mais direta, práticas como a caça e a venda de animais silvestres para consumo humano, são consideradas as principais causas de propagação de doenças zoonóticas (DOBSON et al., 2020; SANGENIS, 2016; ALHO, 2012; JORGE et al., 2010). 
Mas o reduzido conhecimento acerca dos efeitos desses impactos sobre a saúde humana ainda é uma importante lacuna para o gerenciamento do ambiente e da saúde no Brasil e no mundo (IPEA, 2015). Estudos da OMS demonstram que muitos problemas de saúde graves estão intimamente relacionados às perturbações provocadas pelas atividades humanas nos ecossistemas, como, por exemplo, doenças respiratórias, parasitoses e diversas formas de lesões não intencionais (WHO, 2011). Esses problemas são gerados no âmbito das atividades produtivas e no estabelecimento dos núcleos populacionais, implicando na necessidade de pesquisas, do desenvolvimento de tecnologias, de medidas educativas e, principalmente, de políticas públicas voltadas ao saneamento básico, o tratamento de poluentes, o controle de zoonoses e a conservação da biodiversidade e dos ecossistemas naturais.

Além de proporcionar a proteção de sistemas naturais inteiros, as unidades de conservação promovem o equilíbrio ecológico e biogeoquímico, incluindo o controle biológico de pragas e patógenos, a regulação do clima, a manutenção dos solos e a qualidade e quantidade dos recursos hídricos; garantem a segurança alimentar, através da disponibilização de polinizadores para a agricultura e da manutenção da variabilidade genética de espécieschaves; além de proporcionar um rico banco genético para o desenvolvimento da ciência, incluindo as ciências da saúde. Os ecossistemas são essenciais para o desenvolvimento de várias funções biofisiológicas do nosso corpo e, por isso, ecossistemas saudáveis são fundamentais para a saúde e o bem-estar humano (GAUDERETO, 2019; ANNERSTEDT; DEPLEDGE, 2015; RICKLEFS, 2010).

No desenvolvimento das expedições, tivemos não só a oportunidade de comparar a qualidade ambiental dos ecossistemas encontrados nas unidades de conservação com os ecossistemas não protegidos, antropizados ou não, como observamos in loco os serviços ecossistêmicos dessas unidades. Ao registrar córregos, rios, cachoeiras de águas transparentes - a salvo do descarte de esgotos domésticos e industriais - e bacias hidrográficas preservadas dentro de florestas protegidas, em várias das unidades de conservação que trabalhamos, descrevemos processos que possibilitam água de qualidade para milhões de brasileiros. No Parque Nacional do Jaú, no Amazonas, presenciamos a formação dos rios voadores, que garantem a disponibilidade desse recurso para boa parte do Brasil (COPERTINO, 2019).

Nessas unidades, também registramos centenas de espécies que são fundamentais para a segurança alimentar humana e para as ciências da saúde, muitas delas endêmicas, e, a maioria, cada vez mais rara ou ameaçada fora desses ambientes protegidos. No Parque Nacional do Pantanal Matogrossense, encontramos o arroz-do-brejo (Oryza latifolia), que está sendo utilizado como germoplasma em estudos para o melhoramento do arroz cultivado (IBAMA, 2003). No Parque Nacional de Boa Nova, conhecemos várias plantas alimentícias e de uso medicinal, como a umburana (Amburana cearensis) e a caatinga-de-porco (Caesalpinia pyramidalis). Verificamos a riqueza dos campos rupestres do Parque Nacional das Sempre-Vivas em 
plantas hoje estudadas pela ciência, como o matapasto (Ageratum fastigiatum); a gritadeira (Palicourea rigida); a arnica (Lychnophora sp.); a azulzinha (Evolvulus sp.); a quina-da-serra (Remijia ferruginea) e a flor-de-veado (Odontadenia lutea). Registramos plantas emblemáticas como a erva-mate (Ilex paraguariensis) e a araucária (Araucaria angustifolia) no Parque Nacional do Iguaçu.

Estudos estimam o valor monetário do serviço de estocagem da diversidade de plantas em parques nacionais, utilizando como parâmetro os custos de manutenção de plantas nativas em coleções vivas de jardins botânicos. Um desses estudos concluiu que o valor desse tipo de serviço prestado pelos ecossistemas da Serra do Cipó seria de mais de 25 milhões de dólares ano (RESENDE et al., 2013).

Além da importância de todos esses bens e serviços ofertados quase gratuitamente pelas unidades de conservação, os parques nacionais podem propiciar e promover o acesso direto aos benefícios da natureza para a saúde das pessoas (IUCN, 2015). O contato com a natureza através dos parques pode não só melhorar a percepção da sociedade sobre o entendimento da importância dessas áreas para a qualidade de vida e a saúde, como podem colaborar diretamente na promoção da saúde das pessoas, impulsionando atividades esportivas e de lazer, possibilitando experiências recreativas e estéticas, diminuindo o sedentarismo, o estresse e diversos outros fatores que contribuem para o surgimento de transtornos e doenças.

Várias pesquisas recentes mostram os benefícios que essas atividades podem exercer na saúde física e mental dos visitantes de parques nacionais. Mesmo breves contatos com a natureza e a exposição passiva podem resultar em efeitos imediatos. Um desses estudos revela claramente a diminuição dos riscos de depressão. As evidências sobre a melhora da saúde e do bem-estar humanos em ambientes naturais são crescentes, mostrando efeitos benéficos expressivos para a saúde mental (ANNERSTEDT; DEPLEDGE, 2015).

Os efeitos restauradores da exposição ao ambiente natural aumentam a capacidade de lidar e de se recuperar do estresse, de doenças e de lesões. Pesquisas indicam ligações claras entre o tempo gasto ao ar livre na natureza e o aumento da produtividade e da criatividade no trabalho. Parques e outros espaços verdes podem ser contribuidores altamente econômicos para prevenir ou tratar problemas de saúde (IUCN, 2015). No Japão e na China, métodos como o Shinrin-Yoku ou Forest Bathing propiciam "a terapia da natureza como método de promoção da saúde e potencial modelo universal de saúde está implicada na redução do estado de estresse e do tecnostress dos dias modernos" (HANSEN et al., 2017). A ameaça das mudanças climáticas aumentou a conscientização sobre os serviços ecossistêmicos fornecidos pelos parques nacionais e outras áreas protegidas. Parques Saudáveis, Pessoas Saudáveis é um movimento global sobre a importância dos parques para a saúde e o bem-estar das pessoas (IUCN, 2014). Mas ainda estamos longe da compreensão da importância dessas áreas públicas para a saúde humana. 


\section{Uma nova economia preocupada com os ecossistemas, a biodiversidade e as pessoas}

Os esforços de conservação da biodiversidade são cada vez mais dependentes das áreas protegidas, e um fator importante para a conservação dessas áreas é que seu papel seja reconhecido e valorizado pela sociedade. As dificuldades de valorar a contribuição econômica das unidades de conservação foi analisada por Young e Medeiros (2018), que buscaram quantificar a contribuição econômica das unidades de conservação no Brasil, avaliando serviços ecossistêmicos, turismo, produtos florestais, água, carbono e impostos. Eles estimam, por exemplo, que o valor do carbono florestal estocado nas unidades de conservação brasileira é superior a $R \$ 130$ bilhões.

Uma das principais formas que a sociedade tem de entrar em contato com as unidade de conservação é por meio do turismo, sendo esta uma atividade que pode trazer impactos positivos para saúde e bem-estar, pode gerar senso de pertencimento por parte da comunidade, trazer benefícios econômicos e melhorar a qualidade ambiental (McCOOL; SPENCELEY, 2014).

No Brasil, em 2019, a visitação em unidades de conservação federais estabeleceu um novo recorde, com mais de 15,3 milhões de visitas. Isso representou um aumento de $20,4 \%$ em relação ao recorde de 12,4 milhões do ano anterior (BREVES et al., 2020). Em 2018, a contribuição total desses gastos para a Economia nacional possibilitou a geração de 90 mil empregos, $R \$ 2,7$ bilhões em renda, $R \$ 3,8$ bilhões em valor agregado ao PIB e $R \$ 1,1$ bilhão em impostos. A análise mostrou que cada $R \$ 1$ investido no ICMBio em 2018 produziu R $\$ 15$ em benefícios econômicos ao Brasil (SOUZA; SIMÕES, 2019).

A Organização Mundial de Turismo aponta que essa atividade sustentável tem o potencial de contribuir, direta ou indiretamente, para todos os Objetivos do Desenvolvimento Sustentável (ODS). Em particular, foi incluído como meta nos Objetivos 8, 12 e 14, sobre crescimento econômico inclusivo e sustentável, consumo e produção sustentáveis e o uso sustentável dos oceanos e dos recursos marinhos, respectivamente (UNTWO, 2015). O turismo de caráter comunitário em parques nacionais acentua essa sintonia, com a promoção do uso sustentável dos ecossistemas terrestres, a redução da pobreza, a eliminação ou redução da caça ilegal e do tráfico de animais silvestres, entre outras.

O turismo ecológico contribui para o desenvolvimento local, ajuda na organização dos territórios, incentiva o respeito aos ambientes naturais, promove a qualidade de vida através de novas formas de se relacionar com esses lugares, principalmente quando consegue se integrar a outras atividades, como a agricultura familiar e a valorização de produtos e da cultura local. Isso acontece, por exemplo, no entorno do Parque Nacional da Serra da Canastra, em Minas Gerais. Apesar da existência de conflitos desde a criação da unidade, quando terras utilizadas como pastagens passaram a ser integradas ao parque (BARBOSA, 2007), hoje a região é uma referência. O turismo

revista brasileira educação ambiental 
ecológico alavancou a busca por queijos de qualidade, contribuindo para que os atores locais se organizassem para melhorar a produção local (FRAZÃO et al., 2019).

Processos semelhantes, onde o turismo, associado às unidades de conservação, tem promovido a revitalização da economia e, de certa forma, controlado o avanço do agronegócio sobre áreas naturais, ocorrem, por exemplo, na região do Parque Nacional da Chapada dos Veadeiros, do Parque Nacional da Serra do Cipó e do Parque Nacional do Itatiaia.

Uma nova economia que valorize o meio ambiente e o contato das pessoas com a natureza, diversificando e qualificando as atividades produtivas e as culturas locais, também tem um enorme potencial para contribuir positivamente para a saúde e a qualidade de vida. No entanto, em um país continental e desigual como o Brasil, o acesso às unidades de conservação é restrito e limitado. Questões relacionadas à carência de infraestrutura para visitação e a distância dos grandes centros impede que muitos parques nacionais tenham mais visitantes. Apenas 10 dos 74 parques nacionais recebem mais de $80 \%$ de todas as mais de 15,3 milhões de visitas anuais (BREVES et al., 2020). Assim, as unidades de conservação ainda estão bastante distantes do universo da maioria dos brasileiros.

\section{Conclusões}

A série Parques do Brasil é fruto de um amplo processo participativo de construção, apresentando um mosaico de narrativas que explicitam a complexidade da questão ambiental e sua relação com as atividades humanas, a ciência, a qualidade de vida e a saúde. Ela surgiu com o objetivo de promover não só a valorização dessas áreas e de sua biodiversidade, mas de incentivar o desenvolvimento de experiências pessoais nesses lugares, numa perspectiva de busca de novas possibilidades de como lidar e viver num mundo extremamente biodiverso.

As narrativas da série não trazem em si a reflexão, pois o objetivo não é construir objetos que sejam fechados neles mesmos, mas gerar temas para reflexões externas, tais como pontos de partida e não como pontos de chegada. A série não traz as respostas, nem apresenta todas as explicações e informações, é um relato elaborado a várias mãos, a partir de uma experiência compartilhada com muitas outras pessoas, com suas próprias experiências, apresentando, dessa forma, uma síntese do que foi vivenciado nas expedições, num vasto processo educativo transversal.

Esse processo educativo se inicia com a possibilidade do acesso ao conhecimento sobre a existência dessas áreas e sua biodiversidade, abrindo caminho para o empoderamento e para a reflexão. Pois esse acesso, além de ser um direito de todos, pode e deve gerar um efeito reflexivo na compreensão do mundo histórico e das suas relações com a natureza. Educar para a reflexão é, sobretudo, construir diálogos, na busca de uma economia que 
fomente o estado de bem-estar social, por meio de práticas econômicas diversificadas, orgânicas, culturalmente ricas, cooperativas, solidárias e de baixo impacto, que promovam a conservação dos ecossistemas naturais, a biodiversidade, a saúde e a qualidade de vida.

\section{Referências}

ALENCAR, A. et al. Mapping three decades of changes in the Brazilian Savanna native vegetation using Landsat data processed in the Google Earth engine platform. Remote Sensing, v. 12, n. 6, p. 1-23, 2020.

ALHO, C. J. R. Importância da biodiversidade para a saúde humana: uma perspectiva ecológica. Estud. av., São Paulo, v. 26, p. 151-166, 2012.

ANNERSTEDT, M. V. B.; DEPLEDGE, M.H. Healthy people with nature in mind. BMC Public Health, v. 15, p. 1-7, 2015.

BARBOSA, C. Território de Vida e Trabalho dos Pequenos Produtores de Queijo da Serra da Canastra: um estudo sobre a relação entre produção camponesa e espaços naturais protegidos nas nascentes do Rio São Francisco, Minas Gerais. Dissertação de Mestrado. UFU, 2007. $111 \mathrm{f}$. Disponível

em $<$ http://repositorio.ufu.br/bitstream/123456789/16270/1/TerritoriosVidaTrabalho. pdf>. Acesso em 30 maio 2020.

BBC. The hidden toll of lockdown on rainforests, 2020. Disponível em $<$ https://www.bbc.com/future/article/20200518-why-lockdown-is-harming-theamazon-rainforest>. Acesso em 29 maio 2020.

BBC NEWS. Coronavirus: Lions nap on road during South African lockdown, 2020. Disponível em <https://www.bbc.com/news/world-africa-52314282>. Acesso em 1 jun. 2020.

BREVES, G.S.S.; BARBOSA, E.F.P; GARDA, A.B; SOUZA, T.V.S. Monitoramento da Visitação em Unidades de Conservação Federais: Resultados de 2019 e Breve Panorama Histórico. Brasília: ICMBio, 2020.

COPERTINO, M. et al. Desmatamento, fogo e clima estão intimamente conectados na Amazônia. Cienc. Cult., São Paulo, v. 71, n. 4, p. 04-05, 2019.

CECCATO, A. P. S. et al. Mercury Distribution in Organs of Fish Species and the Associated Risk in Traditional Subsistence Villagers of the Pantanal Wetland. Environ Geochem Health, v. 38, n. 3, p. 713-722, 2016.

DEAN, W. A ferro e fogo: a história da devastação da Mata Atlântica brasileira. São Paulo: Companhia das Letras, 1996. 
DELLA GIUSTINA, C. C. Degradação e conservação do Cerrado: uma história ambiental de Goiás. Brasília: Universidade Federal de Brasília, 2013.

DOBSON, A.P. et al. Ecology and economics for pandemic prevention. Science, v. 369, p. 379-381, julho de 2020.

FONSECA, A. et al. Boletim do desmatamento da Amazônia Legal, Abril, 2020. Imazon, Belém, maio de 2020. Disponível em $<$ https://imazon.org.br/publicacoes/boletim-do-desmatamento-da-amazonialegal-abril-2020-sad/>. Acesso em 29 maio 2020.

FRAZÃO, J.P. et al. Os impactos as ações empreendedoras da APROCAN na região da Canastra. Revista Eletrônica Calafiori, v3, n. 2, p. 5-26, 2019.

FRANCO, J. L.; DRUMMOND, J. A. Proteção à natureza e identidade nacional no Brasil: anos 1920-1940. Rio de Janeiro: Editora FIOCRUZ, 2009.

FRANCO, J. L.; DRUMMOND, J. A.; GENTILE, C.; AZEVEDO, A. Biodiversidade e ocupação humana do Pantanal mato-grossense: conflitos e oportunidades. Rio de Janeiro: Garamond, 2013.

FREITAS, C. et al. Ecosystem approaches and health in Latin America. Cad. Saúde Pública, Rio de Janeiro, v. 23, n. 2, p. 283-296, fev. 2007.

GAUDERETO, G. L. et al. Avaliação de serviços ecossistêmicos na gestão de áreas verdes urbanas: promovendo cidades saudáveis e sustentáveis. Ambient. soc., São Paulo, v. 21, 2018.

HANSEN, M.; REO, J.; KIRSTEN, T. Shinrin-Yoku (Forest Bathing) and Nature Therapy: A State-of-the-Art Review. Int. J. Environ. Res. Public Health, v. 14, n.8, 2017.

HOBSBAWN, E.J. A era das revoluções: 1789-1848. Rio de Janeiro: Paz e Terra, 2015.

IBAMA. Plano de Manejo do Parque Nacional do Pantanal Matogrossense. Brasília: IBAMA, 2003.

IBAMA. Plano de Manejo do Parque Nacional das Emas. Brasília: IBAMA, 2004.

IBAMA. Plano de Manejo do Parque Nacional da Serra da Canastra. Brasília: IBAMA, 2005.

IBGE. Mapa de biomas do Brasil, primeira aproximação, 2004. Disponível em <https://www.ibge.gov.br/geociencias/informacoes-ambientais/15842biomas.html?=\&t=downloads $>$. Acesso em 22 jun. 2020.

ICMBio. Plano de Manejo da Estação Ecológica de Taiamã. Brasília: ICMBio, 2016. 
ICMBio. Visitação em Parques Nacionais bate novo recorde em 2018. Brasília: ICMBio, $2020 . \quad$ Disponível em $<$ https://www.icmbio.gov.br/portal/ultimas-noticias/20-geral/10216-visitacao-emparques-nacionais-bate-novo-recorde-em-2018>. Acesso em 1 jun. 2020.

INEA. Plano Estadual de Recursos Hídricos do Estado do Rio de Janeiro. Relatório Gerencial. Rio de Janeiro: INEA, 2014. Disponível em $<$ http://www.inea.ri.gov.br/cs/groups/public/documents/document/zwew/mdcx/ edisp/inea0071538.pdf>. Acesso em 25 jun. 2020.

INPE. Atlas dos remanescentes florestais da Mata Atlântica: Período 20162017. Relatório técnico. São Paulo: INPE, 2018. Disponível em $<$ http://mapas.sosma.org.br/site media/download/Atlas Mata Atlantica 20162017 relatorio tecnico 2018 final.pdf $>$. Acesso em 22 jun. 2020.

INPE. A taxa consolidada de desmatamento por corte raso para os nove estados da Amazônia Legal (AC, AM, AP, MA, MT, PA, RO, RR e TO) em 2019 é de $\mathbf{1 0 . 1 2 9} \mathbf{k m}^{2}$. Disponível em $<$ http://www.inpe.br/noticias/noticia.php?Cod Noticia=5465 >. Acesso em 23 jun. 2020.

IPEA. Impacto do desmatamento sobre a incidência de doenças na Amazônia. Brasília: IPEA, 2015.

JACQUES, H.; BHALLA, N. Workers mauled by pandemic shock to wildlife reserves: national parks, 2020. Disponível em $<$ https://www.reuters.com/article/us-health-coronavirus-environmentconser/workers-mauled-by-pandemic-shock-to-wildlife-reserves-national-parksidUSKBN22H1KN>. Acesso em 1 jun. 2020.

IUCN. Healthy Parks Healthy People: Prepared for Parks Victoria, 2015. Disponível em $<$ https://www.iucn.org/sites/dev/files/content/documents/hphpstateevidence2015.pdf>. Acesso em 2 jun. 2020.

IUCN. A Guide to the Healthy Parks Healthy People: Approach and Current Practices, $2014 . \quad$ Disponível em $<$ https://www.iucn.org/sites/dev/files/content/documents/improving-health-andwell-being-stream-report $0 . p d f>$. Acesso em 15 jun. 2020.

JORGE, R. S. P. et al. Ocorrência de patógenos em carnívoros selvagens brasileiros e suas implicações na saúde pública. Rev. Oecologia Australis, v.14, n 3, p. 686-710, 2010.

MAPBIOMAS. Sistema de Estimativas de Emissões de Gases de Efeito Estufa do Observatório do Clima, 2019. Disponível em $<$ https://mapbiomas.org/infograficos-1?cama set language=pt-BR $>$. Acesso em 16 jul. 2020.

McCOOL, S.F.; SPENCELEY, A . Tourism and protected areas: A growing nexus of challenge and opportunity. Koedoe, v. 56, n. 2, 2014. 
MMA. Cadastro Nacional de Unidades de Conservação. Ministério do Meio Ambiente. Disponível em <https://www.mma.gov.br/areas-protegidas/cadastronacional-de-ucs.html>. Acesso em 28 jan. 2020.

NEWS 18th. Wild Animals Are Strolling Public Places During Coronavirus Lockdown, $2020 . \quad$ Disponível em $<$ https://www.news18.com/photogallery/world/wild-animals-are-strolling-publicplaces-during-coronavirus-lockdown-2586871-2.html>. Acesso em 1 jun. 2020.

OLIVERO, J.; FA, J.E.; REAL, R. et al. Recent loss of closed forests is associated with Ebola virus disease outbreaks. Sci Rep, v.7, n.14291, 2017.

PRADO JÚNIOR, C. História econômica do Brasil. São Paulo: Brasiliense, 2008.

PUREZA, F.; PELLIN, A. e PADUA, C. Unidades de Conservação: Fatos e personagens que fizeram a história das categorias de Manejo. São Paulo: Matriz 2015

RESENDE, FM.; FERNANDES, GW.; COELHO, MS. Economic valuation of plant diversity storage service provided by Brazilian rupestrian grassland ecosystems. Braz. J. Biol. São Carlos, v.73, n.4, p. 709-716, nov. 2013.

RICKLEFS, R.E. A economia da Natureza. Rio de Janeiro: Guanabara Koogan, 2010.

SANCHES, C.; ALVARENGA, L. Parques do Brasil: a concepção de uma série de documentários de história natural e a promoção da conservação da biodiversidade e das unidades de conservação brasileiras. Revista Museologia \& Interdisciplinaridade, Brasília, v. 8, p. 191-209, 2019.

SANGENIS, L. H. C. et al. Transmissão da doença de Chagas por consumo de carne de caça: revisão sistemática. Rev. bras. epidemiol., São Paulo, v. 19, n. 4, p. 803-811, 2016.

SCIENTIFIC AMERICAN EDITORS. Stopping Deforestation Can Prevent Pandemics: Destroying habitats makes viruses and other pathogens more likely to infect humans. Disponível em<https://www.scientificamerican.com/article/stopping-deforestation-canprevent-pandemics1/>. Acesso em 2 jun. 2020.

SILVA, J. M. C.; BARBOSA, L. C. F. Caatinga: the largest dry tropical dry forest region in South America. Cham: Springer International Publishing, 2017.

SOUZA T. V. S. B.; SIMÕES, H. B. Contribuições do Turismo em Unidades de Conservação Federais para a Economia Brasileira: Efeitos dos Gastos dos Visitantes em 2018: Sumário Executivo. Brasília: ICMBio, 2019.

STEFFEN, W. et al. The Antropocene: conceptual and historical perspectives. Londres: The Royal Society Plubishing, 2012. 
SOSMA - Fundação SOS Mata Atlântica. Relatório anual de atividades 2017. São Paulo: SOSMA, 2018. Disponível em <https://www.sosma.org.br/wpcontent/uploads/2019/11/RA SOSMA 2018 DIGITAL.pdf>. Acesso em 25 jun. 2020.

TAYLOR, MICHAEL. The hidden toll of lockdown on rainforests. Disponível em <https://www.reuters.com/article/health-coronavirusdeforestation/deforestation-risks-rise-as-coronavirus-hinders-se-asia-protectionidUSL8N2BJ12Z>. Acesso em 1 jun. 2020.

UMETSU, R. K. et al. Efeito da inundação lateral sobre a distribuição da vegetação ripária em um trecho do rio Cuiabá, MT. Rev. Árvore, Viçosa, v. 35, n. 5, p. 1077-1087, Oct. 2011.

UNWTO. Tourism and Sustainable Development Goals. African Protected Area Conservation and Science, África, v. 56, n 2, a1221, 2015.

WHO - World Health Organization. One Health, 2017. Disponível em $<$ https://www.who.int/news-room/q-a-detail/one-health>. Acesso em 9 jun. 2020.

WHO - World Health Organization. WHO Public Health \& Environment Global Strategy Overview 2011. Disponível em $<$ https://www.who.int/phe/publications/PHE 2011 global strategy overview 20 11.pdf>. Acesso em 2 jul. 2020.

YOUNG, C.E.F; MEDEIROS, R. Quanto vale o verde: a importância econômica das unidades de conservação brasileiras. Rio de Janeiro: Conservação Internacional, 2018. 